\title{
Rancang Bangun Chatbot Sebagai Penghubung Komunikasi Antara Aplikasi Line Messenger Dengan Telegram Messenger
}

\author{
Defri Gentia, I Made Sukarsa, Kadek Suar Wibawa \\ Program Studi Teknologi Informasi, Fakultas Teknik, Universitas Udayana \\ Bukit Jimbaran, Bali, Indonesia, telp. (0361) 701806 \\ e-mail: defrigentia@gmail.com, sukarsa@unud.ac.id, suar wibawa@unud.ac.id
}

\begin{abstract}
Abstrak
Teknologi informasi seiring waktu telah berkembang sangat pesat dengan adanya berbagai aplikasi instant messaging yang bermunculan bertujuan sebagai media komunikasi secara digital. Aplikasi instant messaging telah digunakan diberbagai bidang seperti di dunia pendidikan salah satunya untuk perkuliahan. Penggunaan instant messaging di perkuliahan bertujuan sebagai media untuk berkomunikasi antara mahasiswa dan dosen terkait aktivitas kuliah. Contoh aplikasi instant messaging yang telah digunakan mahasiswa dan dosen yaitu Line Messenger dan Telegram Messenger. Perbedaan instant messaging yang digunakan oleh dosen dan mahasiswa menimbulkan permasalahan dimana mahasiswa biasa menggunakan Line dan dosen menggunakan Telegram, sehingga saat mahasiswa ingin berkomunikasi online dengan dosen maka harus menggunakan aplikasi yang sama dengan yang digunakan oleh dosen yaitu Telegram. Solusi untuk mempermudah komunikasi online antara mahasiswa dan dosen, yaitu dengan pembuatan chatbot, karena bisa dirancang sebagai sistem penghubung komunikasi antara mahasiswa dengan dosen. Chatbot yang dirancang berfungsi sebagai jembatan antara aplikasi Line dengan Telegram. Komunikasi berupa pesan teks yang diberikan baik oleh mahasiswa maupun dosen melalui aplikasi Line ataupun Telegram disimpan oleh chatbot dan dikirim ke instant messaging lawan bicara.
\end{abstract}

Kata kunci: Chatbot, Line Messenger, Telegram Messenger, Instant Messaging

\begin{abstract}
Information technology over time has developed very rapidly with the emergence of instant messaging applications that aim as a digital communication media. Instant messaging applications have been used in various fields such as in education one of which for lectures. The use of instant messaging in lectures aims as a medium to communicate between students and lecturers related to college activities. Examples of applications used by students and lecturers are instant messaging Line Messenger and Telegram Messenger. The difference instant messaging used by lecturers and students raises the problem where ordinary students use Line and lecturers use Telegram, so when students want to communicate online with lecturers they must use the same application with used by lecturers namely Telegram. The solution to facilitate online communication between students and lecturers is by making chatbot, because it can be designed as a communication link system between students and lecturers. Chatbot is designed to function as a bridge between the Line and Telegram applications. Communication in the form of text messages given both by students and lecturers through the Line or Telegram application will be saved by the chatbot and sent to the interlocutor's instant messaging.
\end{abstract}

Keywords: Chatbot, Line Messenger, Telegram Messenger, Instant Messaging

\section{Pendahuluan}

Perkembangan teknologi informasi pada era generasi milenial berkembang pesat seperti pemberian informasi dengan bantuan teknologi sangat memudahkan masyarakat, karena informasi bisa didapat secara cepat, mudah dan gratis. Teknologi informasi dan komunikasi menawarkan berbagai macam kemudahan sehingga semakin diminati oleh 
masyarakat [1]. Kehadiran smartphone merupakan salah satu bentuk alat komunikasi yang digunakan oleh masyarakat. Smartphone menjadi kebutuhan baru bagi masyarakat karena terdapat aplikasi pendukung yang berperan untuk memberikan kemudahan dalam mencari informasi serta melakukan komunikasi dengan orang lain [2]. Munculnya aplikasi-aplikasi dengan berbagai kategori, salah satunya yaitu aplikasi instant messaging yang berperan sebagai komunikasi online antar pengguna. Contoh aplikasi yang banyak menarik perhatian pengguna smartphone yaitu Line dan Telegram.

Aplikasi instant messaging telah digunakan diberbagai bidang seperti di dunia pendidikan salah satunya untuk perkuliahan. Penggunaan instant messaging di perkuliahan bertujuan sebagai media untuk berkomunikasi antara mahasiswa dan dosen terkait tugas, quiz, dan aktivitas kuliah lainnya. Mahasiswa yang dikategorikan sebagai digital native merupakan kalangan yang akrab dengan perkembangan teknologi, mahasiswa juga merupakan kalangan yang menggunakan aplikasi instant messaging Line Messenger sebagai alat komunikasi dengan sesama temannya [2]. Pengguna lain yang memanfaatkan aplikasi instant messaging sebagai alat komunikasi adalah dosen, aplikasinya berupa Telegram Messenger. Perbedaan aplikasi instant messaging yang digunakan oleh dosen dan mahasiswa dapat menimbulkan permasalahan, karena saat berkomunikasi online mahasiswa harus menggunakan aplikasi instant messaging yang sama dengan yang digunakan oleh dosen yaitu Telegram Messenger. Penggunaan aplikasi Telegram menjadi tidak efektif, karena tujuan aplikasi digunakan hanya untuk berkomunikasi dengan dosen walaupun durasi komunikasi singkat, jarang diakses dan terkesan membuang memori penyimpanan smartphone mahasiswa.

Perancangan chatbot menjadi solusinya, karena chatbot bisa dirancang sebagai sistem penghubung komunikasi mahasiswa dan dosen. Chatbot yang dirancang berperan sebagai jembatan antara aplikasi Line Messenger dan Telegram Messenger. Komunikasi berupa pesan teks yang dibuat dan diberikan baik oleh mahasiswa maupun dosen melalui aplikasi Line ataupun Telegram diterima oleh chatbot dan selanjutnya diteruskan ke masing-masing aplikasi tergantung tujuan penerima pesan yang diberikan oleh pengirim pesan. Chatbot bisa saling terintegrasi dengan Line dan Telegram, karena melalui penerapan konsep API.

Penelitian serupa dilakukan oleh Bhavika Ranoliya dengan judul penelitian "Chatbot for University Related FAQs" mengusulkan chatbot diimplementasikan untuk memenuhi kebutuhan akademik. Chatbot dapat membantu siswa untuk mendapatkan informasi seperti ketersediaan layanan, universitas, pembaruan tentang aktivitas yang terjadi di dalam kampus dan informasi akademik lainnya [3]. Penelitian yang dilakukan oleh Dina Fitria memberikan usulan yang berbeda mengenai chatbot sebagai pemberi materi pelajaran yang bisa dibaca siswa dan melakukan latihan soal melalui chatbot pada aplikasi obrolan Line. Guru dapat mengatasi masalah seperti pengoreksian jawaban dan pengumpulan data nilai siswa sehingga dapat mengevaluasi hasil belajar siswa secara mandiri [4]. Penelitian yang dilakukan oleh Grazyna Chaberek-Karwacka dengan judul "E-learning as a tool for improving access to academic education in the opinion of University of Gdansk students and teachers", penelitian yang samasama menjelaskan chatbot e-learning dapat mengurangi aspek-aspek negatif dari perkuliahan paruh waktu. Keuntungan dari pengenalan bentuk pengajaran e-learning, dimana siswa dan guru dapat menghemat waktu dan memfasilitasi pembelajaran [5]. Penelitian yang berujudul " $A I$ and Web-Based Human-Like Interactive University Chatbot (UNIBOT)" yang dibuat oleh Neelkumar P. Patel menjelaskan chatbot dibuat bertujuan sebagai alat yang menyediakan cara cepat untuk berinteraksi dengan pengguna. Pengguna dapat memperoleh informasi yang diinginkan dengan mudah [6].

\section{Metodologi Penelitian}

Perancangan aplikasi chatbot sebagai penghubung komunikasi antara Line Messenger dengan Telegram Messenger terdiri dari beberapa tahapan yaitu: pengumpulan teori, perancangan sistem, pembuatan aplikasi, dan pengujian sistem. Pengumpulan teori bertujuan sebagai acuan dalam perancangan sistem chatbot. Pembuatan sistem berdasarkan rancangan gambaran umum sistem dan flowchart untuk setiap alur proses sistem yang telah dibuat.

\subsection{Pengumpulan Teori}

Metode pengumpulan teori yang digunakan dalam penelitan yaitu kepustakaan. Suatu cara pengumpulan data yang bersumber pada penelitian terdahulu. Pengumpulan teori-teori 
didapatkan dari jurnal ilmiah, buku, e-book, website resmi dan paper publikasi yang diunduh melalui internet.

\subsection{Pembuatan Aplikasi}

Aplikasi atau program chatbot disusun dengan bahasa Hypertext Preprocessor dan menggunakan database MySQL untuk tempat menyimpan data. Program chatbot disimpan pada server HEROKU Cloud agar bisa diakses secara online. Instant messaging yang terintegrasi dengan chatbot adalah Line Messenger dan Telegram Messenger.

\subsection{Perancangan Sistem}

Perancangan chatbot yang dibangun meliputi gambaran umum sistem dan flowchart alur proses sistem. Pembuatan chatbot dimulai dari rancangan berupa gambaran secara abstrak dan selanjutnya gambaran umum sistem chatbot bisa dibuat. Gambaran umum sistem chatbot sebagai penghubung komunikasi antara aplikasi Line dan Telegram terlihat seperti Gambar 1.

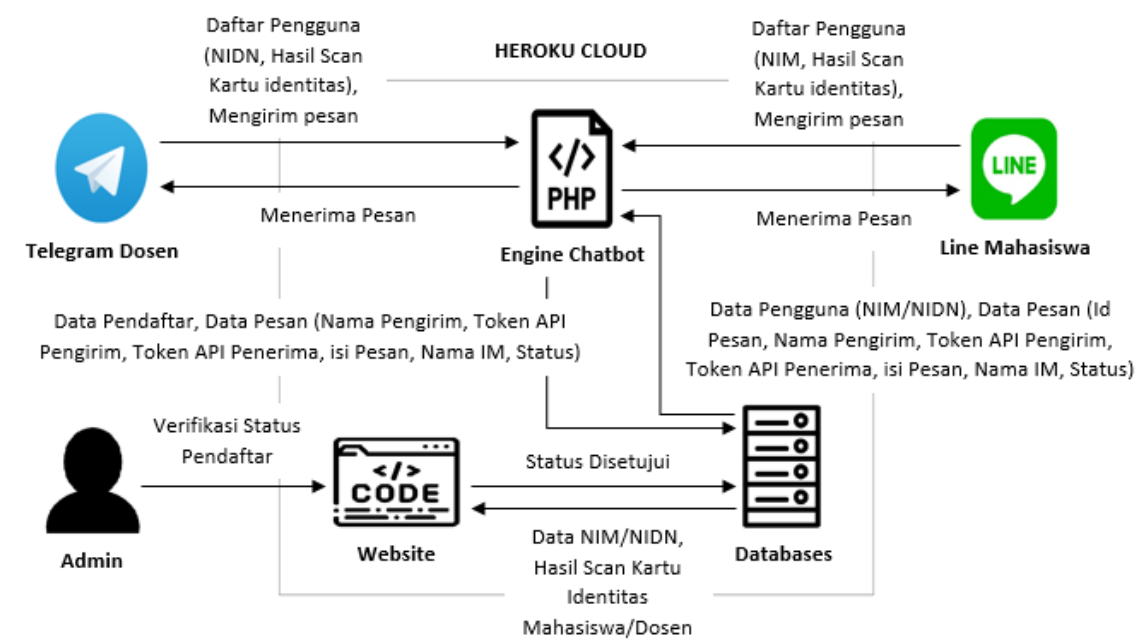

Gambar 1. Gambaran secara umum pada sistem Chatbot

Engine chatbot dibangun dengan bahasa pemrograman PHP, sedangkan website dibuat untuk diakses oleh admin agar bisa memverifikasi pengguna saat mendaftar melalui chatbot. Website dan engine chatbot disimpan pada hosting HEROKU agar admin bisa mengakses website secara online dan engine chatbot bisa terhubung dengan Line serta Telegram. Chatbot sebagai penghubung komunikasi antara aplikasi Line dengan Telegram bertujuan saat mahasiswa memiliki masalah mengenai tugas, quiz yang diberikan oleh dosen ataupun hal lainnya yang berhubungan dengan perkuliahan, maka mahasiswa bisa berkomunikasi langsung secara online dengan dosen terkait. Mahasiswa bisa berkomunikasi langsung dengan dosen tanpa perlu mengunduh aplikasi Telegram Messenger. Dosen dengan menggunakan Telegram Messenger dan mahasiswa menggunakan Line Messenger bisa saling berkomunikasi. 


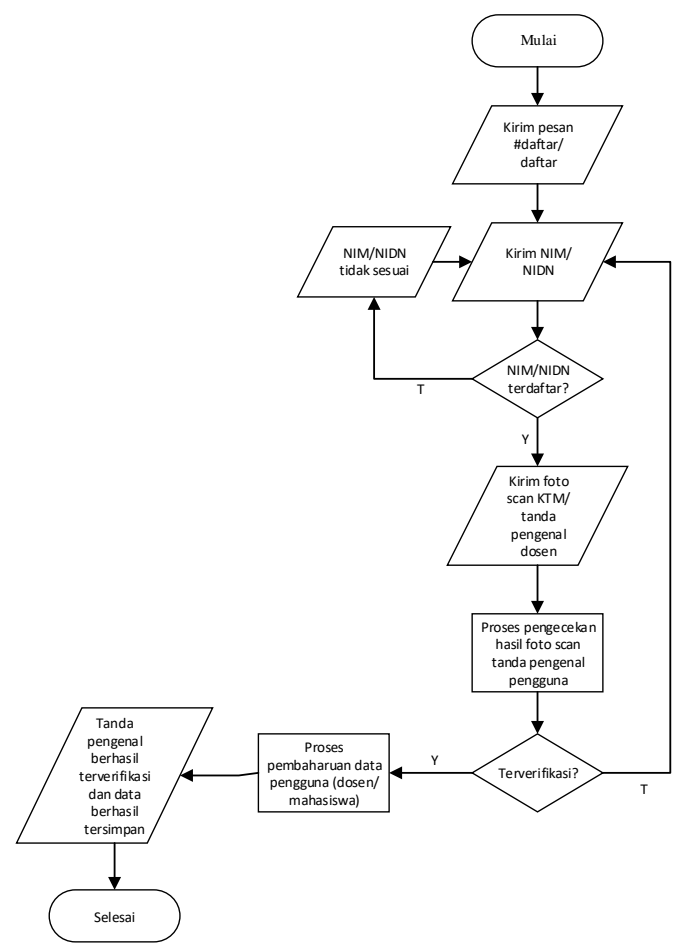

Gambar 2. Flowchart pendaftaran pengguna Chatbot

Alur proses diawali dengan pendaftaran pengguna melalui chatbot pada masing-masing aplikasi baik dari Line maupun Telegram. Pengguna memasukan komen pesan teks "\#daftar" setalah itu chatbot meminta pengguna untuk memasukan NIM/NIDN serta upload hasil scan kartu pengenal pengguna. Admin memverifikasi data pendaftar, jika data sudah benar maka pengguna bisa menggunakan fitur pada chatbot sesuai kebutuhan.

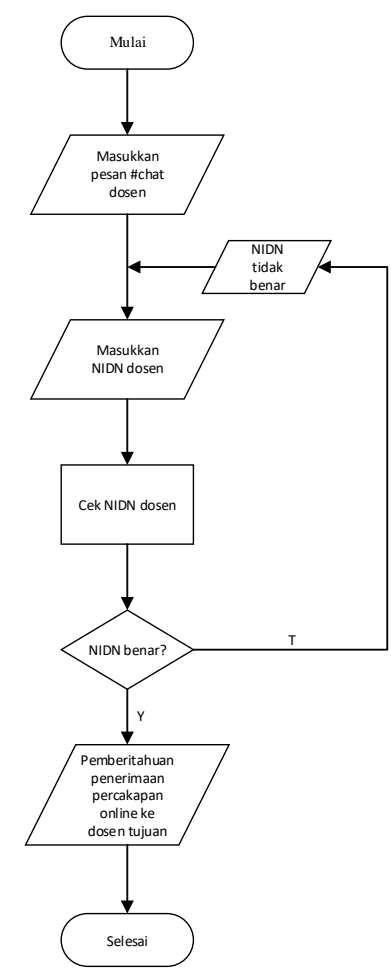

Gambar 3. Flowchart komunikasi online 
Alur proses diawali dari mahasiswa melakukan permintaan dengan memasukan komen berupa pesan teks "\#chat dosen" melalui chatbot Line. Bagian selanjutnya mahasiswa diminta untuk memilih dosen atau memasukan identitas dosen berupa NIDN. Dosen terpilih atau NIDN yang dimasukan divalidasi oleh sistem, jika sudah sesuai permintaan komunikasi online dari mahasiswa dapat dikirim ke chatbot Telegram dosen terpilih. Permintaan dari mahasiswa yang telah disetujui oleh dosen dapat melakukan komunikasi online dengan dosen terpilih.

\section{Kajian Pustaka}

Komponen yang digunakan untuk melakukan penelitian meliputi pembuatan mesin chatbot sebagai penghubung komunikasi dari aplikasi Line ke Telegram begitu pun sebaliknya. Komponen lain berupa aplikasi Line dan aplikasi Telegram. Mesin atau program chatbot dibangun dengan menggunakan beberapa bahan yang dijelaskan sebagai berikut.

\subsection{Chatbot}

Chatbot merupakan suatu sistem yang dapat membalas pesan yang dikirim oleh pengguna. Chatbot disusun atas dua kata yaitu chat dan bot. Chat adalah komunikasi yang dilakukan melalui media tulisan atau pesan. Bot merupakan suatu program yang memiliki suatu pengetahuan yang dapat memberikan respon sesuai perintah yang diberikan. Chatbot dapat memberikan informasi dengan cepat dan efisien. Chatbot dapat melakukan percakapan dengan manusia atau chatbot yang lain. Penerapan metode yang digunakan pada chatbot banyak ditemui seperti framework AIML, metode pattern-matching, sentence similarity measurement dan metode pencocokan lainnya [7]. Chatbot berperan menjadi penghubung komunikasi antara mahasiswa dan dosen walaupun aplikasi yang digunakan berbeda-beda.

\subsection{API}

Suatu fungsi yang dapat digunakan dalam mengembangkan sebuah aplikasi sehingga memudahkan programmer dalam bekerja. Fungsi-fungsi API dapat dibaca ataupun ditulis sehingga aplikasi dapat terintegrasi dengan aplikasi lain. API terdiri dari modul-modul yang dapat digunakan dalam mengembangkan suatu aplikasi secara gratis dan bersifat publik [8]. API adalah rangkaian fungsi yang dapat digunakan untuk sebuah modul pada aplikasi, sama halnya dengan Google Map API yang merupakan peta dunia digital yang dapat diakses secara gratis. API tersedia untuk bisa digunakan pada fungsi sistem file, windowing, dan sistem jaringan [9]. Pada naskah pembuatan chatbot dapat diintegrasikan di aplikasi Line dan Telegram. API yang digunakan dimiliki oleh aplikasi Line Messenger dan Telegram Messenger.

\subsection{Bahasa Pemrograman PHP}

Hypertext Preprocessor adalah pemrograman yang dapat berjalan diatas webserver dan menyediakan halaman web kepada pengunjung website. PHP dapat disisipkan pada halaman website, sehingga programmer dengan mudah membuat konten secara dinamis. Proses berjalannya script PHP dimulai dari user meminta suatu halaman website yang dituliskan melalui address bar pada browser. Webserver dapat mengenali URL yang di request oleh script, sehingga dapat mengintruksikan untuk memproses script. PHP berjalan dan mengirimkan request halaman dari user ke browser web, dimana user melihatnya melalui monitor [10]. Bahasa pemrograman PHP menjadi bagian penting dalam penelitian, karena pembuatan chatbot dibangun menggunakan pemrograman PHP. Terdapat 20 file dibuat dalam membangun mesin chatbot.

\subsection{MySQL}

MySQL merupakan suatu program server yang dapat menerima serta mengirimkan data dengan cepat dan menggunakan perintah SQL (Structured Query Language). MySQL dapat mengakses database yang berperan sebagai Server, dan program atau aplikasi berada pada posisi client [11]. Hasil manajemen data dari chatbot tersimpan pada database MySQL. Struktur-struktur tabel untuk menampung data dibuat melalui database MySQL dengan nama software yaitu SQLyog.

\subsection{HEROKU}

Heroku merupakan sebuah platform hosting dengan basis cloud, Heroku digunakan dalam mengembangkan aplikasi berbasis website serta mendukung pemrograman seperti PHP, 
Java, Python, Ruby, dan lainnya. Kriteria Heroku termasuk PaaS atau disebut Platform as a Service, sehingga pengembangan aplikasi cukup hanya dengan melakukan konfigurasi yang terkait dengan aplikasi. Pengelolaan konfigurasi berupa ram, sistem operasi, dan sebagainya agar Heroku dapat melakukan pendeteksi bahasa yang digunakan pada suatu aplikasi [12]. Heroku berperan sebagai penyimpanan online, agar chatbot bisa terintegrasi dengan aplikasi Line dan Telegram sehingga bisa digunakan oleh pengguna terutama mahasiswa dan dosen secara online. File PHP serta database yang dibangun untuk penelitian disimpan pada cloud Heroku.

\subsection{Line Messenger}

Line merupakan aplikasi yang berperan sebagai pengirim dan penerima pesan secara langsung melalui berbagai perangkat seperti smartphone, komputer, dan lainnya. Line dapat berjalan sesuai fungsinya dengan bantuan jaringan internet agar pengguna bisa melakukan suatu aktivitas yaitu membaca pesan, mengirim pesan berupa teks, suara, video, gambar, dan lainnya [13]. Penerapan chatbot pada aplikasi Line diawali dengan mendaftar untuk membuat channel bot pada website Line Bussiness. Pendaftaran dilakukan untuk mendapatkan sebuah token yang berfungsi sebagai key agar mesin chatbot dapat terhubung dengan channel bot yang telah didaftarkan.

\subsection{Telegram Messenger}

Telegram merupakan pesan langsung yang bisa digunakan oleh pengguna untuk berkomunikasi secara online setelah melakukan tahap pendaftaran akun telegram pada aplikasi Telegram. Syarat pendaftaran akun telegram hanya memerlukan nomor telepon sebagai tahap verifikasi bahwa akun benar milik pengguna pendaftar. Perancangan chatbot agar terintegrasi dengan aplikasi Telegram diawali dengan melakukan pendaftaran bot baru pada akun Fatherbot melalui aplikasi Telegram. Pendaftaran dilakukan untuk mendapatkan sebuah key yang berfungsi agar chatbot dapat terhubung dengan channel atau akun bot yang telah didaftarkan pada aplikasi Telegram.

\section{Hasil dan Pembahasan}

Membahas mengenai hasil implementasi dari perancangan sistem chatbot dan pengujian sistem chatbot. Pembahasan aplikasi berupa implementasi integrasi API Line dan API Telegram, implementasi basis data, implementasi antarmuka chatbot, pengujian sistem, dan evaluasi UAT (User Acceptance Test). Hasil yang dimaksud adalah analisa dari hasil pengujian aplikasi yang telah dikembangkan.

\subsection{Implementasi Integrasi API Line dan API Telegram}

Protokol komunikasi pada perancangan sistem chatbot menghubungkan API Line dan API Telegram, dimana database chatbot sebagai jembatan yang menghubungkannya. Kunci penting agar API dapat terhubung yaitu pengambilan parameter key token pengguna di Line dan Telegram. Key token pengguna hanya bisa diberikan oleh server Line dan Telegram, key token bersifat unik. Pengguna harus melakukan pendaftaran melalui chatbot yang ada di Line untuk mahasiswa dan Telegram untuk dosen. Pendaftaran bertujuan untuk mendapatkan key token pengguna berdasarkan NIM/NIDN pengguna. API Line dan API Telegram bisa saling berkomunikasi saat key token pengguna telah tersimpan dengan tipe data string pada database. Contoh protokol komunikasi, dimana mahasiswa mengirimkan pesan ke dosen tujuan berdasarkan NIDN dosen yang dimasukan. Server Line dapat memberikan key token mahasiswa beserta isi pesan dengan format JSON. Proses pencocokan NIDN dosen yang diberikan mahasiswa dengan yang ada di database dilakukan, jika NIDN tersedia pada database maka key token pengguna untuk NIDN tersebut dipanggil dan disimpan pada baris yang sama dengan key token mahasiswa beserta isi pesan yang telah diterjemahkan kedalam tipe data string. Key token dosen disimpan pada kolom key token tujuan dan key token mahasiswa tersimpan di kolom key token asal. Penyimpanan data key token asal, key token tujuan, isi pesan, tipe IM, dan status pesan dilakukan pada tabel pesan. Engine API Telegram melakukan pencocokan jika pada tabel pesan terdapat status pesan "terkirim" untuk key token tujuan Telegram, maka isi pesan diberikan ke server Telegram beserta key token tujuan agar server Telegram dapat mengirimkan pesan ke tujuan yang tepat. Status pesan diubah menjadi "diterima" jika proses pencocokan berhasil. 


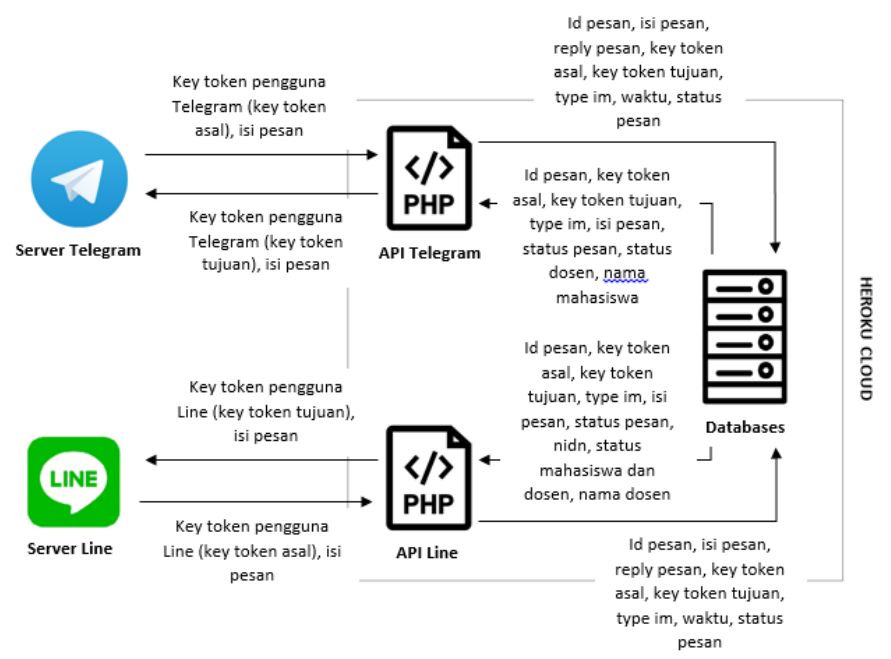

Gambar 4. Implementasi integrasi API Line dan API Telegram

\subsection{Implementasi Databases}

Perancangan databases atau basis data menggunakan program MySQL dengan penggunaan bahasa perintah SQL. Basis data chatbot terdiri dari tabel mahasiswa, tabel dosen, dan tabel pesan. Tabel-tabel yang terdapat dalam basis data memiliki kamus data, dimana adalah penjelasan secara tertulis mengenai data yang tersimpan didalam basis data.

Tabel 1. Kamus data tabel mahasiswa

\begin{tabular}{cccc}
\hline Atribut & Tipe & Panjang Data & PK \\
\hline id_mahasiswa & integer & 11 & Ya \\
nomor_urut & integer & 11 & \\
nama & varchar & 50 & \\
id_api & varchar & 50 & \\
id_identitas & integer & 11 & \\
link_ktm & text & - & \\
type & enum & '0', '1', '2', 'online_chat', 'segera_chat' & \\
status_mahasiswa & enum & 'line' \\
\hline
\end{tabular}

Tabel 2. Kamus data tabel dosen

\begin{tabular}{cccc}
\hline Atribut & Tipe & Panjang Data & PK \\
\hline id_dosen & integer & 11 & Ya \\
nomor_urut & integer & 11 & \\
nama & varchar & 50 & \\
id_api & varchar & 50 & \\
id_identitas & integer & 11 & \\
link_ktd & text & - & \\
type & enum & 'telegram' & \\
keterangan & enum & 'admin', 'dosen' & \\
status_dosen & enum & '0', '1', '2', 'online_chat', 'segera_chat' & \\
\hline
\end{tabular}

Tabel 3. Kamus data tabel pesan

\begin{tabular}{cccc}
\hline Atribut & Tipe & Panjang Data & PK \\
\hline id_chat & integer & 11 & Ya \\
isi_chat & text & - & \\
reply_pesan & text & - &
\end{tabular}




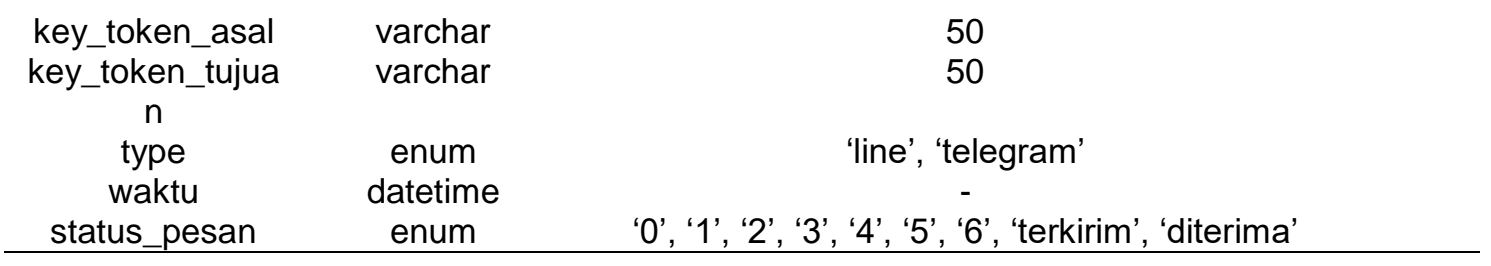

\subsection{Implementasi Antarmuka Chatbot}

Pembuatan antarmuka sistem chatbot yang terintegrasi dengan aplikasi Line dan Telegram berhasil terbentuk. Pembuatan sistem chatbot dituangkan dalam kode program berdasarkan gambaran umum dan flowchart yang dirancang. Program chatbot dibangun dengan terdiri dari file API Line dan file API Telegram dengan format PHP. File PHP berisi sintaks Query untuk menghubungkan chatbot dengan database yang berperan sebagai media penyimpanan data.

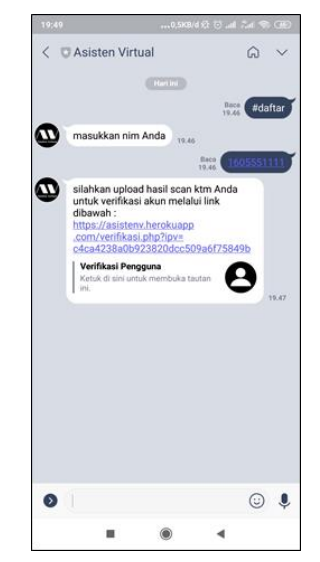

Gambar 5. Antarmuka pendaftaran pengguna mahasiswa

Pendaftaran pengguna melalui chatbot hanya untuk memastikan bahwa mahasiswa telah terdaftar pada channel chatbot di aplikasi Line Messenger. Mahasiswa bisa menggunakan fitur komunikasi online dengan dosen melalui aplikasi Line Messenger setelah mendaftar. Mahasiswa hanya perlu memasukkan pesan "\#daftar", identitas mahasiswa yaitu NIM (Nomor Induk Mahasiswa), dan hasil scan kartu pengenal identitas mahasiswa, karena identitas seperti nama lengkap dan NIM telah tersedia sebelumnya pada database.

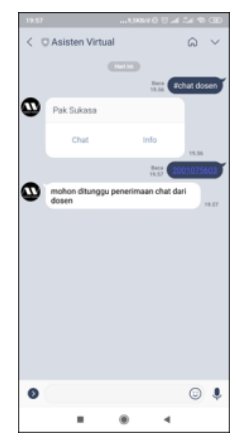

(a)

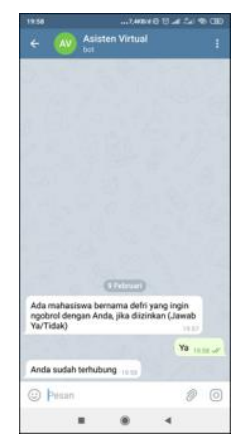

(b)

Gambar 6. (a) Antarmuka permintaan komunikasi online (b) Antarmuka penerimaan komunikasi Online

Permintaan komunikasi online bertujuan agar dosen mendapatkan dua opsi untuk menerima permintaan dari mahasiswa atau menolaknya. Permintaan komunikasi diteruskan ke 
dosen yang dituju berdasarkan NIDN dosen yang dimasukan oleh mahasiswa. Proses penerimaan komunikasi online dari mahasiswa dilakukan oleh dosen.

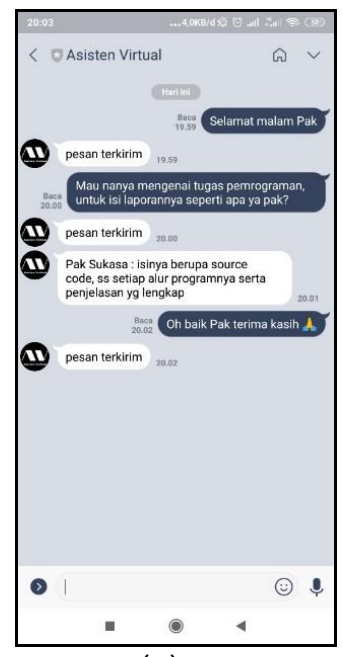

(a)

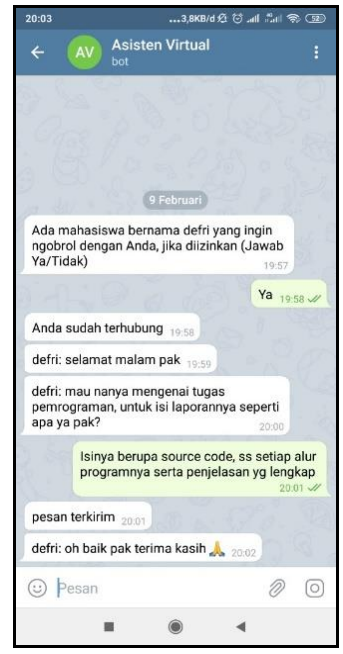

(b)

Gambar 7. (a) Antarmuka komunikasi online melalui Line (b) Antarmuka komunikasi online melalui Telegram

Tujuan komunikasi online antara mahasiswa dan dosen dibuat jika ada tugas dan quiz yang tidak dimengerti serta komplain mengenai tugas ataupun quiz, maka mahasiswa bisa menghubungi dosen melalui chatbot. Instant messaging yang bisa digunakan adalah Line Messenger untuk mahasiswa dan Telegram Messenger untuk dosen. Komunikasi online dapat diakhiri jika mahasiswa atau dosen telah mengirimkan pesan "\#reset".

\subsection{Pengujian Sistem}

Pengujian chatbot yang dilakukan berupa metode Black Box. Kasus uji yang dipersiapkan ada 11, dan setelah tahap pengujian dari 11 kasus uji yang dilakukan, aplikasi chatbot berhasil lolos $100 \%$. Metode terdiri dari komponen pengujian pada setiap kasus uji, masukan yang diberikan, dan status untuk setiap komponen.

Tabel 4. Hasil pengujian metode Black Box

\begin{tabular}{|c|c|c|}
\hline Komponen Pengujian & Masukan & Status \\
\hline Operasi Create untuk mahasiswa & Admin menambah mahasiswa & Diterima \\
\hline Operasi Create unt & Admin menambah dosen & Diterima \\
\hline Pendaftaran akun mahasiswa & $\begin{array}{c}\text { Mahasiswa memasukan NIM dan hasil } \\
\text { scan KTM }\end{array}$ & Diterima \\
\hline Pendaftaran akun dosen & $\begin{array}{c}\text { Dosen memasukan NIDN dan hasil scan } \\
\text { kartu pengenal dosen }\end{array}$ & Diterima \\
\hline Validasi pendaftaran pengguna & $\begin{array}{c}\text { Admin memvalidasi akun pengguna } \\
\text { pendaftar }\end{array}$ & Diterima \\
\hline Error handling & $\begin{array}{l}\text { Pengguna memasukan komen pesan yang } \\
\text { tidak tersedia pada chatbot }\end{array}$ & Diterima \\
\hline Permintaan komunikasi online & $\begin{array}{c}\text { Mahasiswa memasukan komen pesan } \\
\text { \#chat dosen }\end{array}$ & Diterima \\
\hline $\begin{array}{l}\text { Pengiriman Permintaan komunikasi } \\
\text { online }\end{array}$ & $\begin{array}{l}\text { Mahasiswa memilih dosen atau } \\
\text { memasukan NIDN dosen }\end{array}$ & Diterima \\
\hline $\begin{array}{l}\text { Penerimaan permintaan komunikasi } \\
\text { online }\end{array}$ & Dosen membalas pesan "ya" & Diterima \\
\hline Penolakan permintaan komunikasi & Dosen membalas pesan "tidak" & Diterima \\
\hline
\end{tabular}


online

Reset komunikasi online

Pengguna memasukan komen pesan

Diterima \#reset

\subsection{Evaluasi Hasil UAT}

UAT atau disebut User Acceptance Test merupakan sebuah proses untuk melakukan pengujian dengan hasil sebuah dokumen yang dapat digunakan sebagai bukti bahwa aplikasi diterima serta memenuhi kebutuhan. Pemberian kuesioner dilakukan untuk mendapatkan tanggapan dari responden atau user dalam menggunakan aplikasi chatbot penghubung komunikasi yang dibuat. Kuesioner UAT (User Acceptance Test) telah disebar langsung ke 25 mahasiswa. Kuesioner berisi 6 pertanyaan dimana terdapat jawaban yang terdiri beberapa tingkatan yaitu tingkatan 1 (Kurang Baik), tingkatan 2 (Cukup Baik), tingkatan 3 (Baik) dan tingkatan 4 (Sangat Baik). Pertanyaan terbagi menjadi 3 aspek meliputi aspek kemudahan, aspek pencapaian tujuan dan aspek apresiasi. Kuesioner yang telah disebar serta dinilai oleh 25 responden didapatkan hasil pada Tabel 5.

Tabel 5. Hasil UAT (User Acceptance Test) aspek kemudahan

\begin{tabular}{|c|c|c|c|c|c|}
\hline \multirow[b]{2}{*}{ No. } & \multirow[b]{2}{*}{ Pertanyaan } & \multicolumn{4}{|c|}{ Skala Ukur } \\
\hline & & $\begin{array}{c}1 \\
\text { (Kurang } \\
\text { Baik) }\end{array}$ & $\begin{array}{c}2 \\
\text { (Cukup } \\
\text { Baik) }\end{array}$ & $\begin{array}{c}3 \\
\text { (Baik) }\end{array}$ & $\begin{array}{c}4 \\
\text { (Sangat } \\
\text { Baik) }\end{array}$ \\
\hline 1. & $\begin{array}{l}\text { Apakah anda merasa terbantu } \\
\text { menggunakan chatbot sebagai } \\
\text { penghubung komunikasi antara mahasiswa } \\
\text { dan dosen terkait informasi perkuliahan? }\end{array}$ & 0 & 4 & 14 & 7 \\
\hline 2. & $\begin{array}{l}\text { Melalui chatbot yang ada di aplikasi Line } \\
\text { Messenger mahasiswa bisa melakukan } \\
\text { percakapan secara online dengan dosen, } \\
\text { menurut penilaian anda apakah fitur } \\
\text { percakapan online memberikan anda } \\
\text { kemudahan dalam melakukan percakapan } \\
\text { secara online dengan dosen? }\end{array}$ & 0 & 3 & 13 & 9 \\
\hline & Jumlah Nilai & 0 & 7 & 27 & 16 \\
\hline & Persentase Nilai & $0 \%$ & $14 \%$ & $54 \%$ & $32 \%$ \\
\hline
\end{tabular}

Berdasarkan hasil UAT (User Acceptance Test) untuk aspek kemudahan terlihat nilai tertinggi yang diperoleh pada tingkatan 3 dengan jumlah poin sebanyak 27 poin dengan persentase $54 \%$ yang berarti baik, selanjutnya diikuti pada tingkatan 4 berjumlah 16 poin dengan persentase $32 \%$ yang berarti sangat baik. Tingkatan 2 memiliki jumlah poin sebesar 7 poin dengan persentase $14 \%$ yang berarti cukup baik, dan pada skala ukur tingkatan 1 didapat 0 poin. Kesimpulan dari hasil UAT pada aspek kemudahan, menunjukkan penilaian tertinggi adalah $54 \%$ yang berarti BAIK.

Tabel 6. Hasil UAT (User Acceptance Test) aspek pencapaian tujuan

\begin{tabular}{clcccc}
\hline & \multicolumn{1}{c}{ Pertanyaan } & \multicolumn{4}{c}{ Skala Ukur } \\
\cline { 3 - 6 } No. & $\begin{array}{c}\mathbf{1} \\
\text { (Kurang } \\
\text { Baik) }\end{array}$ & $\begin{array}{c}\mathbf{2} \\
\text { (Cukup } \\
\text { Baik) }\end{array}$ & $\begin{array}{c}\mathbf{3} \\
\text { (Baik) }\end{array}$ & $\begin{array}{c}\mathbf{4} \\
\text { (Sangat } \\
\text { Baik) }\end{array}$ \\
\hline 1. & $\begin{array}{l}\text { Setalah menggunakan chatbot, Apakah } \\
\text { penyampaian informasi mengenai } \\
\text { perkuliahan baik dari dosen ataupun } \\
\begin{array}{l}\text { mahasiswa cepat tersampaikan? } \\
\text { Bagaimana menurut penilaian anda }\end{array}\end{array}$ & 0 & 8 & 9 & 8 \\
2. & 0 & 1 & 19 & 5 \\
\hline
\end{tabular}




\begin{tabular}{llccc}
\hline $\begin{array}{l}\text { setelah menggunakan chatbot apakah fitur } \\
\text { percakapan online mahasiswa dengan } \\
\text { dosen berfungsi baik? }\end{array}$ & & & & \\
\hline Jumlah Nilai & 0 & 9 & 28 & 13 \\
\hline Persentase Nilai & $0 \%$ & $18 \%$ & $56 \%$ & $26 \%$ \\
\hline
\end{tabular}

Hasil UAT (User Acceptance Test) menunjukan pada aspek pencapaian tujuan untuk nilai tertinggi diperoleh oleh skala ukur tingkatan 3 dengan jumlah poin sebanyak 28 poin dengan persentase $56 \%$ yang berarti baik. Tingkatan 4 berjumlah 13 poin dengan persentase $26 \%$ yang berarti sangat baik, untuk tingkatan 2 memiliki jumlah poin sebesar 9 poin dengan persentase $18 \%$ yang berarti cukup baik, pada skala ukur tingkatan 1 didapat 0 poin. Kesimpulan dari hasil UAT pada aspek pencapaian tujuan, menunjukkan penilaian tertinggi dengan persentase $56 \%$ yang berarti BAIK.

Tabel 7. Hasil UAT (User Acceptance Test) aspek apresiasi

\begin{tabular}{|c|c|c|c|c|c|}
\hline \multirow[b]{2}{*}{ No. } & \multirow[b]{2}{*}{ Pertanyaan } & \multicolumn{4}{|c|}{ Skala Ukur } \\
\hline & & $\begin{array}{c}1 \\
\text { (Kurang } \\
\text { Baik) }\end{array}$ & $\begin{array}{c}2 \\
\text { (Cukup } \\
\text { Baik) }\end{array}$ & $\begin{array}{c}3 \\
\text { (Baik) }\end{array}$ & $\begin{array}{c}4 \\
\text { (Sangat } \\
\text { Baik) }\end{array}$ \\
\hline 1. & $\begin{array}{l}\text { Bagaimana menurut penilaian anda } \\
\text { mengenai kelayakan penggunaan dari } \\
\text { chatbot sebagai media penghubung } \\
\text { komunikasi antara dosen dan mahasiswa? }\end{array}$ & 1 & 4 & 14 & 6 \\
\hline 2. & $\begin{array}{l}\text { Menurut penilaian anda, apakah chatbot } \\
\text { lebih praktis sebagai media komunikasi } \\
\text { antara dosen dan mahasiswa? }\end{array}$ & 0 & 8 & 13 & 4 \\
\hline & Jumlah Nilai & 1 & 12 & 27 & 10 \\
\hline & Persentase Nilai & $2 \%$ & $24 \%$ & $54 \%$ & $20 \%$ \\
\hline
\end{tabular}

Aspek apresiasi menunjukan hasil UAT (User Acceptance Test) untuk nilai tertinggi diperoleh tingkatan 3 dengan jumlah poin sebanyak 27 poin dan persentase $54 \%$ yang berarti baik. Tingkatan 2 dengan jumlah poin 12 poin dan persentase $24 \%$ yang berarti cukup baik, selanjutnya untuk tingkatan 4 memiliki jumlah poin sebesar 10 poin dengan persentase $20 \%$ yang berarti sangat baik, dan untuk skala ukur tingkatan 1 didapat jumlah 1 poin dengan persentase $2 \%$. Kesimpulan dari hasil UAT pada aspek apresiasi, menunjukkan penilaian tertinggi adalah BAIK dengan persentase $54 \%$.

\section{Kesimpulan}

Rancang bangun chatbot sebagai penghubung komunikasi telah dibuat dengan komponen dan bahan berupa pembuatan API Line dan API Telegram dengan bahasa pemrograman PHP, rancangan basis data menggunakan MySQL, penggunaan HEROKU Cloud, dan pembuatan channel akun bot pada Line serta Telegram yang telah dipersiapkan. Pembuatan chatbot berdasarkan dari perancangan flowchart untuk setiap alur proses dan terhubung dengan basis data. Metode Black Box digunakan dalam pengujian program chatbot untuk memastikan chatbot saat melayani pengguna berjalan dengan baik. Pengujian dimulai dari uji pendaftaran pengguna, uji verifikasi pendaftar, uji permintaan komunikasi online, uji penerimaan komunikasi online, uji mengakhiri komunikasi online, uji error handling. Berdasarkan hasil UAT (User Acceptance Test), menunjukkan penilaian tertinggi berada pada skala ukur 3 yaitu BAIK untuk aspek kemudahan, aspek pencapaian tujuan dan aspek apresiasi.

\section{Daftar Pustaka}

[1] D. Susanti and N. Nurdiana, "Pengaruh Pemanfaatan Teknologi Informasi terhadap Kualitas Pelayanan Mahasiswa," JSil (Jurnal Sist. Informasi), vol. 5, no. 2, pp. 40-45, 2018. 
[2] B. R. Irianto, F. Yusanto, and B. P. S. Putri, "Pengaruh Penggunaan Instant Messaging Line terhadap Efektifitas Komunikasi Interpersonal (Analisa pada Mahasiswa IImu Komunikasi Angkatan 2011 Dan 2014 Fakultas Komunikasi Dan Bisnis Universitas Telkom)," e-Proceeding Manag. ISSN 2355-9357, vol. 2, no. 3, pp. 4216-4222, 2015.

[3] B. R. Ranoliya, N. Raghuwanshi, and S. Singh, "Chatbot for university related FAQs," 2017 Int. Conf. Adv. Comput. Commun. Informatics, ICACCI 2017, vol. 2017-Janua, pp. 1525-1530, 2017.

[4] D. F. Murad, E. Fernando, M. Irsan, S. A. Murad, P. M. Akhirianto, and M. H. Wijaya, "Learning support system using chatbot in 'Kejar C Package' homeschooling program," 2019 Int. Conf. Inf. Commun. Technol. ICOIACT 2019, pp. 32-37, 2019.

[5] G. Chaberek-Karwacka and M. Malinowska, "E-learning as a tool for improving access to academic education in the opinion of University of Gdansk students and teachers," Proc. 2015 Int. Conf. Interact. Mob. Commun. Technol. Learn. IMCL 2015, no. November, pp. 78-82, 2015.

[6] N. P. Patel, D. R. Parikh, D. A. Patel, and R. R. Patel, "Al and Web-Based Human-Like Interactive University Chatbot (UNIBOT)," Proc. 3rd Int. Conf. Electron. Commun. Aerosp. Technol. ICECA 2019, pp. 148-150, 2019.

[7] I. N. S. Paliwahet, I. M. Sukarsa, and I. K. Gede Darma Putra, "Pencarian Informasi Wisata Daerah Bali Menggunakan Teknologi Chatbot," Lontar Komputer, vol. 8, no. 3, p. 144, 2017.

[8] M. Fajar Ramdani, "Pembangunan Aplikasi Informasi, Pengaduan, Kritik, Dan Saran Seputar Kota Cimahi Pada Platform Android," J. IIm. Komputer dan Informasi, vol. 14, no. 1, p. 9, 2017.

[9] A. Hanafi, I. M. Sukarsa, and A. A. K. Agung Cahyawan Wiranatha, "Pertukaran Data Antar Database Dengan Menggunakan Teknologi API," Lontar Komputer, vol. 8, no. 1, p. 22, 2017.

[10] K. Y. Mahartha, P. W. Buana, and I. M. Sukarsa, "Aplikasi Pengolah Data Lokasi GPS Menggunakan SMS Gateway," J. IIm. Merpati (Menara Penelitian Akademika Teknologi Informasi), vol. 2, no. 3, pp. 301-307, 2016.

[11] Gede Indrawan, I. Setyawan. Database MySQL dengan Pemograman PHP. Depok: PT RajaGrafindo Persada. 2019.

[12] https://www.heroku.com, diakses tanggal 2 Mei 2020.

[13] https://line.me/en, diakses tanggal 2 Mei 2020. 